\title{
A REPRESENTAÇÃO DO FEMININO EM PROPAGANDAS DE CERVEJA: EM BUSCA DO ETHOS PERDIDO
}

\author{
Edgar Godoi GABRIEL ${ }^{1}$ \\ Mestre em Linguística Aplicada e Estudos da Linguagem - PUC-SP
}

\begin{abstract}
RESUMO:
Em tempos de luta pela igualdade de gênero e mobilização feminista, este trabalho tem dois objetivos: analisar as estratégias enunciativas que sustentam a mudança de posicionamento da cervejaria Skol em relação à retratação do feminino em sua propaganda e refletir criticamente sobre a possibilidade de tal mudança considerando a atual conjuntura sócio-histórica. Para isso, baseia-se na Análise do Discurso em sua vertente enunciativo-discursiva, tal qual preconizada por Dominique Maingueneau, de quem acionamos a noção de ethos discursivo. Coletado digitalmente, o corpus consiste em cartazes da Skol que circularam em diferentes momentos. Os resultados mostram que, além das razões éticas e morais em consonância com a atualidade, a mudança de um posicionamento mais sexista para um feminista pode ter sido ocasionada sobretudo por questões econômicas.

Palavras-chave: Análise do Discurso francesa. Ethos discursivo. Machismo e objetificação na publicidade de cervejarias.
\end{abstract}

\section{Introdução}

Em trabalhos anteriores (MENDES; GABRIEL, 2018; GABRIEL, 2018), analisamos como é engendrada e trabalhada exaustivamente a imagem de si no material publicitário de institutos educacionais, com vistas à imediata adesão do coenunciador e, por conseguinte, o acesso deste ao mundo ético proposto pela marca (mundo ético dos estudantes empreendedores, dos que ascendem socialmente por tornarem-se bilíngues etc.). Para se alcançar o êxito, as instituições têm os seus textos compostos por profissionais habilitados que dominam as técnicas de expressão e as estratégias enunciativas (redatores publicitários, marqueteiros...).

Neste artigo, deparamo-nos com uma situação bastante atípica no universo da publicidade: a marca utiliza-se dessas técnicas e estratégias a fim de desconstruir o próprio passado, ao mudar seu posicionamento em relação à representação do feminino em sua propaganda. Para isso, conta com ações que promovem a diversidade e o empoderamento feminino, bem como com o trabalho de oito ilustradoras que, "sob um novo olhar", recriam cartazes antigos da marca. Trata-se da campanha "Redondo é sair do seu passado", lançada em 8 de março de 2017, em virtude do Dia Internacional das Mulheres, veiculada pela Skol.

\footnotetext{
${ }^{1}$ Endereço eletrônico: edgargabrielti@gmail.com.
} 
Quando uma empresa estabelece um Outro no material publicístico, esse Outro no geral refere-se à concorrência, com o intuito de se sobressair de algum modo. O que a Skol fez na campanha ora analisada foi trazer o próprio passado na figura do "Outro" e do qual, doravante, ela tenta se "desvincular”. No entanto, ela não o faz, como de costume, atribuindo esse passado a uma causa exterior para então esquecê-lo ou abafá-lo, e sim como um marco factual da sua mudança de posicionamento em relação à retratação do feminino. Uma mudança desse porte, entre discursos tão antagônicos quanto o machista e o feminista, implica necessariamente a ruptura de suas práticas discursivas e, portanto, da imagem de si que se constrói (ethos discursivo).

Este trabalho tem dois objetivos: 1) analisar as estratégias enunciativas que sustentam tal mudança focando no ethos discursivo que emerge dessas ações; 2) refletir criticamente sobre a possibilidade de se retificar a imagem de si construída durante anos por meio da publicidade, considerando o contexto sócio-histórico que viabilizou essa ruptura. Para tanto, ancoramo-nos no arcabouço teórico-metodológico da Análise do Discurso, em sua vertente enunciativodiscursiva tal qual preconizada por Dominique Maingueneau (2008a, 2008b, 2008c, 2014, 2016), de quem lançamos mão dos estudos sobre o ethos discursivo.

O texto é dividido em três partes. Na primeira, delineamos a noção de ethos discursivo que embasa esta discussão. Em seguida, retomamos brevemente dois casos que motivaram a marca a mudar sua atitude, ou seja, as condições de produção desse novo posicionamento. $\mathrm{Na}$ sequência, encontram-se a análise dos pôsteres coletados e, finalmente, nossas considerações sobre essa "virada ética", suas condições de êxito e problematizações.

\section{A noção de ethos discursivo: algumas considerações}

Maingueneau (2008a) ressalta que um discurso não deve ser pensado somente como um conjunto de textos, mas também como uma prática discursiva, a qual implica uma comunidade discursiva que, além de legitimar tal prática, gerencia a produção, a circulação e o consumo dos textos. A fim de estabelecer uma identidade a uma dada comunidade, é preciso que os membros incorporem tais ou quais práticas enquanto se rejeitam outras, ou seja, as práticas discursivas estão submetidas a um sistema de coerções semânticas: a semântica global.

A semântica global é um conjunto elaborado por Maingueneau (2008a, p. 75-98) que rege o universo de sentidos de uma formação discursiva. Visando a sustentar suas hipóteses, o autor elenca sete itens por meio dos quais se pode depreender esse universo: intertextualidade, 
vocabulário, temas, estatuto do enunciador e do destinatário, dêixis enunciativa, modo de enunciação e modo de coesão.

Segundo o teórico, um procedimento que se funda sobre uma semântica "global" não privilegia este ou aquele plano, mas integra-os ao mesmo tempo, ou seja, não há um plano mais importante ou que sintetize os outros. Em seguida, ressalta ainda que essa lista

[...] não é objeto de uma elaboração teórica suficiente para pretender definir um modelo de textualidade. Sua única finalidade é ilustrar a variedade das dimensões abarcadas pela perspectiva de uma semântica global, e nada impede de isolar outras ou de repartir diferentemente as divisões propostas. (MAINGUENEAU, 2008a, p. 77 — grifo acrescido)

Com essa “concessão", sentimo-nos aptos a explorar com mais ênfase somente o modo de enunciação, devido a questões metodológicas condizentes com os nossos objetivos, embora recorramos indiretamente aos demais itens da lista proposta pelo autor.

Retomando, a semântica global é o meio pelo qual se "filtram", entre outros, quais textos são trazidos para o interior da formação discursiva e quais são evitados e/ou traduzidos na forma de simulacro do Outro. Com efeito, se se determina o que pode ser dito, igualmente se direciona o modo como um enunciado pode ser dito/lido. Esse "modo de enunciação" é posteriormente nomeado ethos discursivo, o qual emerge no e pelo discurso.

Legado ao nosso tempo graças aos trabalhos do filósofo grego Aristóteles, conforme nos informa Amossy (2014), o termo ethos foi tomado emprestado da Retórica e, desde a Grécia Antiga, "[...] designa a imagem de si que o locutor constrói em seu discurso para exercer uma influência sobre o alocutário"(CHARAUDEAU; MAINGUENEAU, 2012, p. 220).

Com Gênese dos discursos, Maingueneau (2008a) foi um dos primeiros a introduzir a noção de ethos na Análise do Discurso, embora não o tenha feito enquanto "ethos" propriamente dito, e sim como "modo de enunciação". O autor pondera que a noção de ethos retórica suscita muitas dificuldades de operacionalização, devido ao fato de ela ser "muito intuitiva", isto é, "sem uma definição teórica clara". Por isso, propõe uma noção que, mesmo não sendo essencialmente infiel à concepção cunhada por Aristóteles, ultrapassa em muito o quadro da Argumentação/Retórica (MAINGUENEAU, 2008b; 2008c; 2014).

Desse modo, a noção de ethos é trabalhada para além da eloquência (quando da comunicação na modalidade oral) e tem o seu alcance alargado, abarcando também os textos escritos. Com efeito, ainda que o denegue, o texto escrito também possui uma vocalidade que pode se manifestar em uma multiplicidade de tons que, por sua vez, dá autoridade àquilo que é ou está sendo dito. 
“Tom”, neste caso, é um termo empregado por conta da sua polivalência, ou seja, vale tanto para o escrito quanto para o oral: o tom de um livro, de uma cor, de uma nota musical etc. (MAINGUENEAU, 2008a). Esses tons permitem que o par correlato da enunciação, o coenunciador, construa uma representação do corpo do enunciador. É precisamente desse enunciador - a instância discursiva, não o locutor empírico — que emerge uma instância subjetiva que desempenha o papel de fiador do discurso (MAINGUENEAU, 2008b; 2008c).

"A noção de ethos, que mantém um laço crucial com a reflexividade enunciativa, permite articular corpo e discurso para além de uma oposição empírica entre oral e escrito" (MAINGUENEAU, 2008c, p. 17). Essa articulação, continua o autor, recobre não somente a dimensão verbal, mas também o conjunto de determinações físicas e psíquicas ligado ao fiador pelo arsenal de representações coletivas (os estereótipos), que podem se ratificar, atenuar ou retificar durante o ato de fala.

Assim, com base em representações sociais avaliadas positiva ou negativamente, o coenunciador constrói a figura do fiador a partir de índices diversos liberados durante a enunciação do próprio enunciador. E a figura do fiador implica um caráter, isto é, uma gama de traços psicológicos (machista, moralista, quadrado...), e uma corporalidade que é “[...] ligada a uma compleição física e uma maneira de vestir-se", de habitar o mundo, de se mover no espaço social (MAINGUENEAU, 2008c, p. 18).

Além de persuadir pelo argumento, o discurso visa a fazer com que o coenunciador se identifique tanto com o caráter quanto com a corporalidade da instância que enuncia, pois as ideias criam a adesão do leitor por meio de uma maneira de dizer que também é uma maneira de ser. Dito de outra forma, o discursivo visa a fazer com que o coenunciador incorpore o mundo ético que a enunciação constrói (o mundo ético dos esportistas, astros de cinema etc.).

Essa incorporação, isto é, a ação do ethos sobre o coenunciador, opera em três registros indissociáveis (MAINGUENEAU, 2016, p. 14):

1. A enunciação confere uma corporalidade ao fiador, ela lhe dá corpo.

2. O coenunciador incorpora, assimila através da enunciação um conjunto de esquemas que correspondem a uma maneira específica de se relacionar com o mundo.

3. Essas duas primeiras incorporações permitem a constituição de um corpo, da comunidade imaginária dos que aderem ao mesmo discurso.

No entanto, ainda que o ethos esteja crucialmente ligado ao ato de enunciação, devese lembrar que é possível, e bastante provável, construir representações do enunciador mesmo 
antes que ele se pronuncie de fato, seja porque o texto pertence a um determinado gênero de discurso (entrevista, aula, palestra, reunião...), seja a partir do seu posicionamento ideológico (feminista, capitalista, ecologista...), isto é, tudo contribui para a criação de expectativas em matéria de ethos.

Por conta disso, Maingueneau (2008b) estabelece uma distinção entre o ethos prédiscursivo e o ethos discursivo: o primeiro diz respeito à gama de informações sobre o enunciador antes que este fale e que podem ser adquiridas por diversos meios; o segundo é a imagem de si que o enunciador constrói por meio da sua fala.

Durante sua enunciação, o enunciador não precisa afirmar categoricamente "Sou isso/ Não sou aquilo", mas caso o faça - dependendo do gênero discursivo, essa é uma manobra enunciativa bastante apreciada e requisitada — , estamos diante do que Maingueneau (2008b; 2016) distingue entre ethos dito e ethos mostrado: o "dito" consiste naquilo que o locutor diz sobre si mesmo; já o "mostrado" representa aquilo que o locutor mostra em sua forma de enunciar, e que nem sempre está em sintonia com o primeiro.

Assim, tendo em mente o material ora analisado, ao veicular seus textos comerciais expondo modelos hipersensualizadas que servem ao homem na beira da praia ou no bar, a Skol afirma que, ao consumir o seu produto, o cliente tem acesso a esse mundo ético viril, hétero, descontraído, de quem lança seus gracejos às garçonetes etc. Ainda, que a empresa não só se eximia de combater a cultura do assédio, como também incentiva tais práticas, ou seja, reflete o discurso machista. A cada enunciação, entretanto, a empresa tem a chance de atenuar, reforçar ou desconstruir o que previamente se sabe sobre ela.

Na sequência, retomamos brevemente dois momentos em que a empresa se envolveu em questões polêmicas por causa do seu posicionamento e que foram fundamentais para sua mudança de postura diante do tema retratação do feminino na propaganda.

\section{A (re)contextualização dos fatos: o ápice das críticas a um determinado mundo ético}

A historiografia da publicidade nos fornece dados satisfatórios para depreender qual é o lugar atribuído à mulher nos diversos anúncios publicitários veiculados nas últimas décadas. Há um segmento específico que, nos últimos anos, tem se destacado por "pintar" a mulher da maneira mais controversa: as campanhas das cervejarias.

Embora a cerveja em si não seja um produto diretamente relacionado ao erotismo, tampouco ao consumo exclusivo dos homens, as peças publicitárias de cervejarias em sua 
maioria utilizam-se de modelos hipersensualizadas (existe um tipo predeterminado de beleza) servindo cerveja ao homem. Não entraremos no mérito de que o homem estatisticamente consome mais cerveja do que a mulher e afins. Fato é que o público-alvo desse tipo de campanha tem sido quase que exclusivamente o masculino heterossexual.

Uma dessas cervejarias é a Skol, a qual faz parte do grupo Ambev e tem o maior alcance no mercado brasileiro, ou seja, é a marca de cerveja mais valiosa do Brasil e a quinta no mundo. Além de bebidas, a empresa é responsável pela promoção de eventos esportivos e culturais, por esse motivo, mantém um contato bem próximo e constante com o público jovem. A seguir, tratamos de dois casos emblemáticos relacionados à marca.

Em 2006, a Skol foi autuada pelo Procon-SP em razão da campanha Musa do Verão, na qual consta que "Se o cara que inventou a Skol tivesse inventado a musa do verão, ela estaria disponível a todo mundo". Enquanto esse trecho é narrado em tom de lamentação, o vídeo destaca uma modelo loira de biquíni dourado (a Musa do Verão 2006) em um laboratório de clonagem humana e, segundos depois, é reproduzida e transportada para ser entregue em vários domicílios, aos seus compradores. Detalhe: em todas entregas, a musa se mostra dócil, receptiva e disponível aos homens que compraram um exemplar.

O Procon-SP alegou que a campanha retratava a mulher como "objeto disponível”. A empresa recorreu, mas, em abril de 2016, o Tribunal de Justiça de São Paulo manteve a aplicação da multa. Apesar da condenação, tanto o vídeo em questão quanto outros materiais podem ser facilmente consultados na internet.

Entre outras campanhas de mesmo teor, a do carnaval de 2015 foi a que teve o maior número de críticas negativas para a marca. Naquela ocasião, a cervejaria veiculou sua publicidade com frases ambíguas, das quais uma se destacou: Esqueci o "não" em casa.

Note-se que a frase em si não carrega nenhuma polêmica, já que esse "eu" não indica o gênero do locutor. Deve-se lembrar, porém, que naquele período o país passava por uma efervescência política a despeito dos rumores do pedido de impeachment de Dilma Rousseff, recém-eleita, o que trouxe à tona a discussão sobre o patriarcado vigente - seus adversários políticos teriam subido o tom pelo fato de ela ser mulher; nas ruas, parte da população a ofendia com imagens e frases sexistas. Além disso, ecoava cada vez mais forte nos grandes centros urbanos, sobretudo durante festas populares como o carnaval, a luta pelo fim da cultura do estupro, do feminicídio etc., visto que os dados oficiais são alarmantes ${ }^{2}$.

\footnotetext{
${ }^{2}$ Segundo os dados oficiais das secretarias estaduais de segurança, o Brasil contabilizou 47.646 casos de estupro em 2014; em 2013, esse número chegou a 51.090. Para a diretora-executiva do Fórum Brasileiro de Segurança Pública, Samira Bueno, o número pode ser ainda maior, uma vez que esse é "o tipo de crime que apresenta a maior
} 
A frase repercutiu, de fato, graças a duas moradoras da capital paulista que alteraram a mensagem de um outdoor da marca. A publicitária e ilustradora Pri Ferrari e a jornalista Mila Alves adicionaram E trouxe o nunca na sequência da frase inicial. Ao publicarem o protesto em suas respectivas páginas nas redes sociais com o pedido de que se denunciasse a campanha ao Conselho Nacional de Autorregulamentação Publicitária (Conar), milhares de pessoas comentaram e replicaram a mensagem em poucas de horas. Tal movimento reverberou a ponto de ocasionar um contato direto do diretor de comunicação da Ambev com a dupla para discutir possibilidades e soluções.

Em suma, sob a acusação de "apologia ao estupro", todo o material que continha a frase Esqueci o "não" em casa foi recolhido. A empresa posicionou-se por meio de nota:

\begin{abstract}
As peças em questão fazem parte da nossa campanha "Viva RedONdo", que tem como mote aceitar os convites da vida e aproveitar os bons momentos. No entanto, fomos alertados nas redes sociais que parte de nossa comunicação poderia resultar em um entendimento dúbio. E, por respeito à diversidade de opiniões, substituiremos as frases atuais por mensagens mais claras e positivas, que transmitam o mesmo conceito. Repudiamos todo e qualquer ato de violência seja física ou emocional e reiteramos o nosso compromisso com o consumo responsável. Agradecemos a todos os comentários.
\end{abstract}

Passados alguns dias as peças substitutas foram lançadas. Desta feita, com ligeira mudança em seu conteúdo. Por exemplo, o slogan da campanha pedia respeito: Neste carnaval, respeite, além de enunciados do tipo: Tomou bota? Vai atrás do trio; Quando um não quer, o outro vai dançar; Não deu jogo? Tire o time de campo, entre outras.

Observe-se que, mesmo multada em 2006, a empresa continuou a ratificar seu ethos pré-discursivo, isto é, a endossar aquele comportamento socialmente compartilhado a seu respeito. Dito de outra forma, a empresa continuou a reproduzir um mundo ético no qual bares e festas populares, locais e situações em que o seu produto é mais comumente consumido, como um habitat majoritariamente masculino.

Foi somente com a oposição das mulheres - por meio de movimentos sociais e mobilização nas redes sociais etc. —, que a empresa foi levada a refletir sobre sua postura. Precisou de uma grande reação contrária das mulheres, ao exigir um posicionamento mais coerente e ético da empresa em sua publicidade, para a Skol rever o seu discurso.

taxa de subnotificação do mundo". Disponível em: http://g1.globo.com/politica/noticia/2015/10/n-oficial-deestupros-cai-mas-brasil-ainda-tem-1-caso-cada-11-minutos.html. Acesso em: 23 dez. 2018.

${ }^{3}$ Ao receber diversas denúncias, o Conar analisou o caso e decidiu pelo seu arquivamento. Pode-se consultar a decisão em: http://www.conar.org.br/processos/detcaso.php?id=4082. Acesso em: 23 dez. 2018. 
Repare-se que, enquanto estava no nível jurídico, pouco mudou. A decisão por mudanças surge impulsionada pela ameaça de boicote ${ }^{4}$ à marca por parte das mulheres e simpatizantes. Neste ponto, percebeu-se que a cerveja não era um produto consumido exclusivamente pelo público masculino. Essa revisão de postura, ao que tudo indica, não se limitou ao produto publicístico e acabou alterando também a estrutura da empresa, como será abordado no próximo item.

\section{Retificação do ethos discursivo: aceitação, subversão e manutenção}

Neste item, discorremos sobre a mudança das práticas discursivas e do posicionamento da empresa em relação à retratação da mulher na publicidade, o que implica fazer circular uma outra imagem de si. Para isso, partimos de um cartaz (Figura 1) referente à campanha multada pelo Procon-SP em 2006, analisado brevemente com o intuito de marcar essa transformação, a qual se materializa paulatinamente em campanhas subsequentes (Figuras 2, 3 e 4).

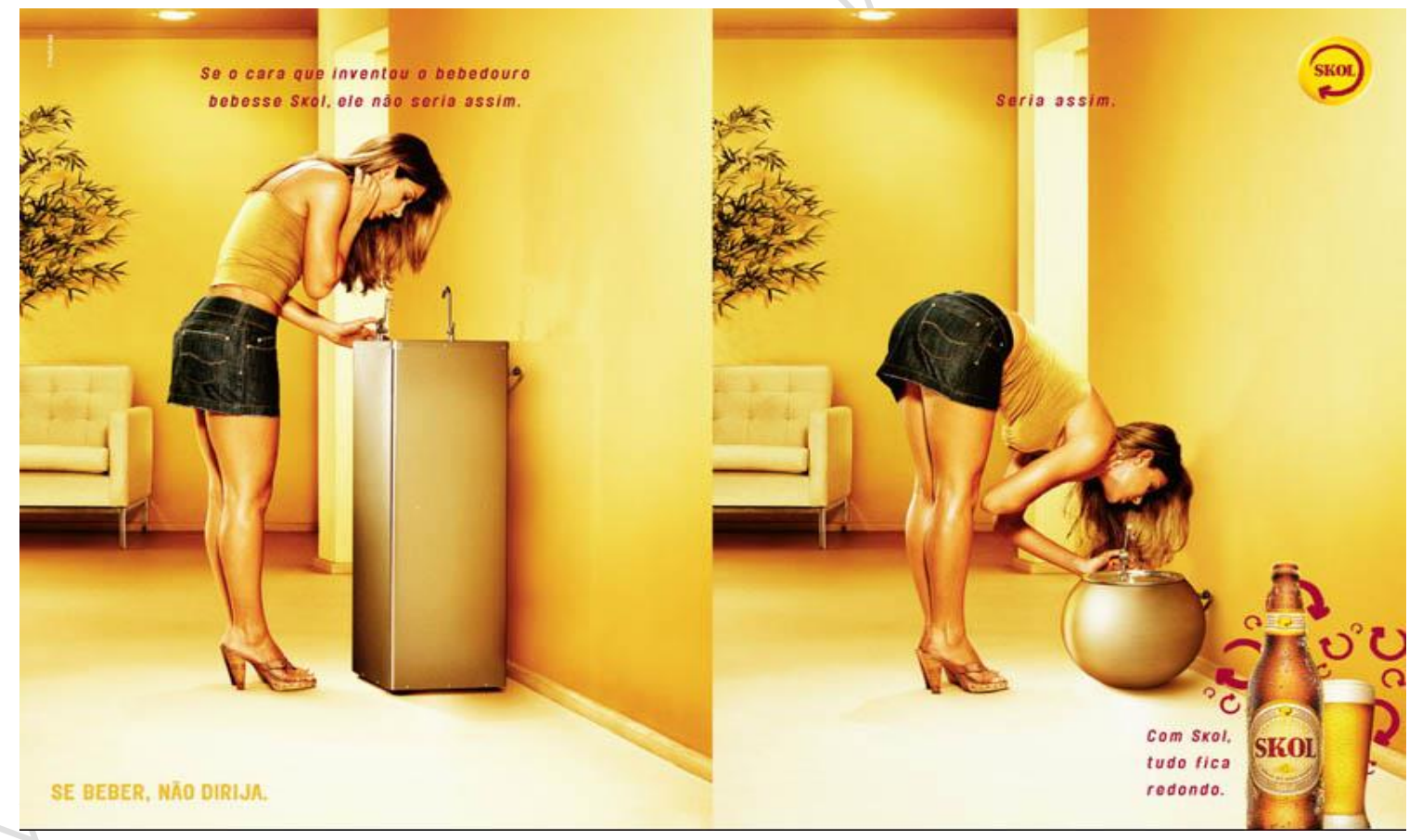

Figura 1.

Disponível em: https://www.buzzfeed.com/copyranter/13-of-the-most-sexist-beer-ads-of-all-time. Acesso em: 24 dez. 2018.

\footnotetext{
${ }^{4}$ Uma característica peculiar da Era Digital é a velocidade com que grupos anunciam boicote a empresas. Por razões econômicas óbvias, nenhuma empresa quer seu nome pichado junto à opinião pública. Estabelecem-se, deste modo, o jogo de pressões e a máxima comercial de que o cliente tem sempre razão.
} 
Essa peça é parte de uma série de seis cartazes que segue a temática "Se o cara que inventou X bebesse Skol, X seria assim”. Nesse rol, incluem-se o bebedouro, o controle remoto, a gorjeta do garçom, o sutiã, o provador de roupas e a tarja de censura. Em todos eles, vê-se ao final o observador masculino em vantagem, seja despindo as partes intimas femininas ao diminuir a tarja de censura, seja ao presenciar a mulher em posição insinuante ao tomar água.

Na Figura 1, encontramos um cartaz dividido em duas cenas. Na primeira, à esquerda, vemos um enunciado em tipografia estilizada da marca com os dizeres "Se o cara que inventou o bebedouro bebesse Skol, ele não seria assim". Em seguida, tem-se uma mulher com roupas curtas e sapatos de salto alto levemente inclinada em direção ao bebedouro para tomar água. Aqui, pode-se depreender a referência ao slogan da marca, pois o bebedouro é "quadrado" (pop. algo/alguém antiquado, careta, convencional), por isso, o enunciado expressa categoricamente que "[...] não seria assim", isto é, o oposto do mundo ético que se oferece.

Na segunda cena, à direita, tem-se o enunciado "Seria assim", ao lado do logotipo da marca, no qual podemos ver nitidamente uma seta circular que representa o "redondo". Em relação à modelo, esta se encontra bastante inclinada, em uma posição que sugere o ato sexual, bebendo água num bebedouro menor e redondo, no formato de um vaso de plantas. Nas proximidades desse bebedouro, encontramos o slogan "Com Skol, tudo fica redondo", seguido de uma garrafa da cerveja e um copo cheio do líquido, com iconotextos da tampa em formato redondo no seu entorno. Ou seja, na cena à direita, tudo é "redondo..."

Além do mais, o cartaz como um todo remete à sensualidade feminina, desde o tom cromático do cenário, o qual simula o bronzeado (temperatura elevada, verão...), até as roupas da modelo (minissaia, blusinha e sapatos de salto alto), seu penteado e seus gestos.

Pode-se alegar qualquer coisa com esse pôster, menos que nele a personagem feminina demonstra sentir qualquer prazer ou conforto. Dito com outras palavras, no mundo ético que se pinta, a representação feminina é a de objeto, uma vez que nem ao menos um gole de cerveja a personagem toma, e sim água (uma possível alusão ao universo top model: não consumir bebidas alcoólicas e manter-se saudável, ou melhor, em forma).

Essa maneira de representar o feminino na propaganda somada às crises internas que se seguiram na empresa por conta do imbróglio de 2015 justificaram a troca da diretoria. Com a entrada de uma diretora de marketing, a corporação sinalizou a direção que tomaria.

O primeiro passo dado nesse sentido foi a publicação de uma série de vídeos temáticos às vésperas do dia 28 de junho de 2016, quando se celebra o Dia do Orgulho LGBTQI, uma 
referência ao episódio Stonewall Inn, em Nova Iorque (EUA), ocorrido em 1969. Em um desses vídeos, intitulado "Estrada", pode-se ler na descrição:

A estrada fica mais colorida quando não se está sozinho. Cada passo é um avanço. Cada abraço, uma conquista. Respeitar a diversidade é o caminho. Dê o play e siga com orgulho. ${ }^{5}$

O filme narra a "estrada" que um rapaz aparentemente homossexual percorre e na qual enfrenta pessoas de diversas ordens sociais e seus preconceitos para/com a homossexualidade. Ao final, pessoas não membros da comunidade LGBTQI, mas pertencentes às minorias, se juntam ao rapaz no gesto simbólico de segurar as mãos uns dos outros e caminharem na mesma direção. Depreende-se desse comercial um apontamento para a diversidade, ou seja, houve um movimento de apartar a marca do mundo ético viril dos heterossexuais exaltado em campanhas anteriores, ao mesmo tempo em que inclui outros perfis.

Entretanto, a primeira campanha publicitária posta a desconstruir o passado veio a público no verão de 2016/2017, cujo mote é "Redondo é sair do seu quadrado". Com a veiculação de três filmes na TV, no rádio e na internet, bem como uma série de cartazes, tal qual a Figura 2, a Skol prega a pluralidade de cores, idades e biótipos.

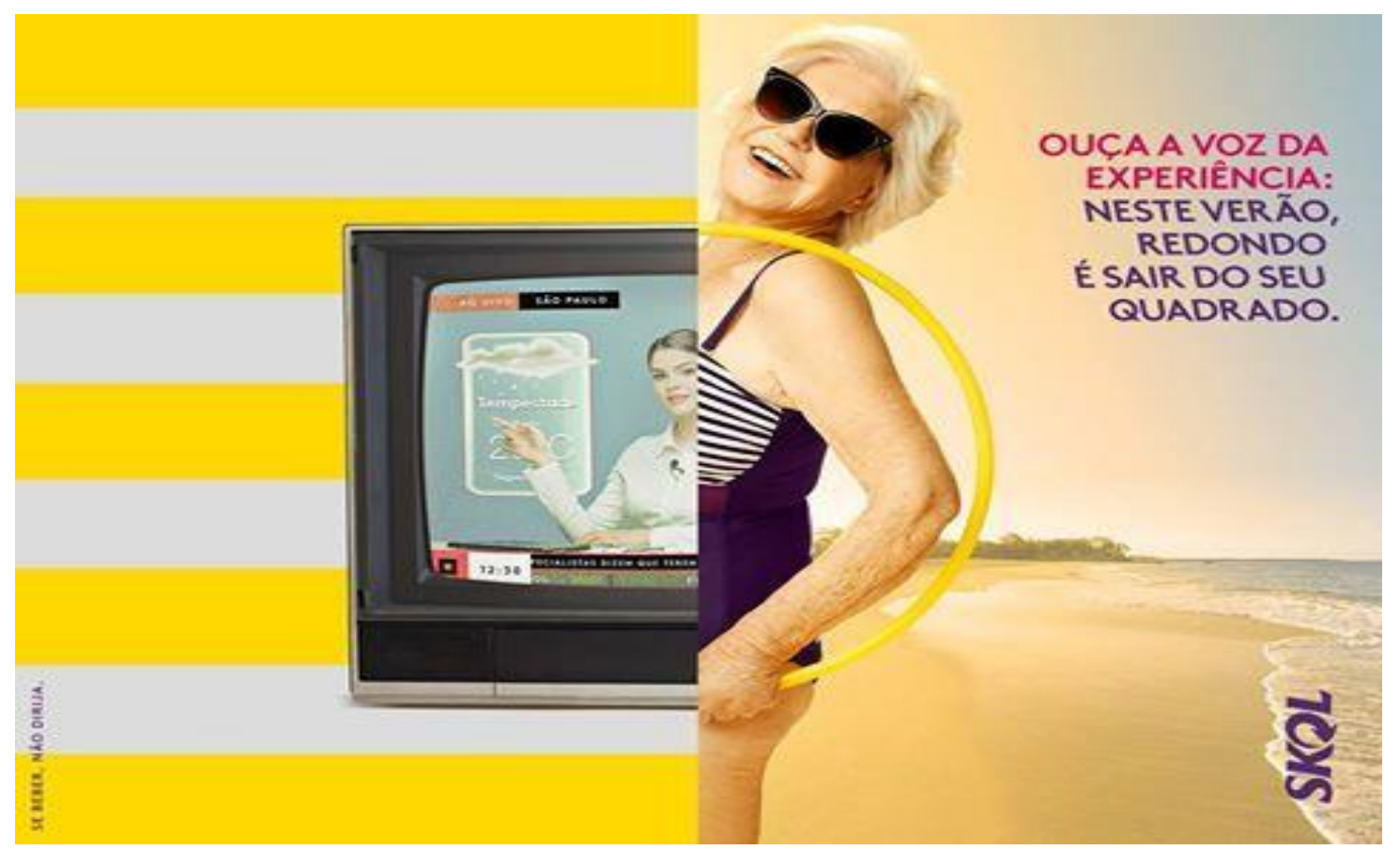

Figura 2.

Disponível em: https://revistapronews.wordpress.com/2017/01/02/campanha-da-skol-reforca-que-verao-e-pratodo-mundo/. Acesso em: 26 dez. 2018.

\footnotetext{
${ }^{5}$ Disponível em: https://www.youtube.com/watch?v=dzc5BPgyEi0. Acesso em: 26 dez. 2018.
} 
A figura consiste em duas cenas. A metade à esquerda é composta de faixas amarelas e faixas brancas; ao centro, há um aparelho televisor analógico antigo onde uma moça jovem apresenta a previsão do tempo. A metade à direita, por outro lado, retrata uma senhora de idade avançada vestindo um maiô e brincando com um bambolê na areia da praia. Na metade à esquerda, todas as formas geométricas remetem ao "quadrado" (TV, faixas horizontais, quadro do tempo...); na metade à direta, tudo fica "redondo" (bambolê, lentes dos óculos de sol, ondas).

Entra em cena uma senhora que "saiu do seu quadrado" (monotonia, rotina, cores pastéis, TV...), e que agora está no "redondo", ou seja, dia ensolarado, alegria, curtição na praia sem se importar com as formas corporais que o tempo lhe proporcionou, o que destoa em muito do que se vinha veiculando, a saber, jovens de corpo escultural que exibem sensualmente suas curvas enquanto estão servindo a cerveja.

Na parte superior, à direita, lê-se “Ouça a voz da experiência: neste verão, redondo é sair do seu quadrado". Note-se que, embora sejam cores diferentes, não há qualquer marca de discurso relatado (seta, balão etc.), o que torna o slogan propositalmente ambíguo. Com isso, o enunciado, que parte de um pré-construído (“ouça a voz da experiência”), pode ser atribuído tanto à fiadora (personagem ao lado) quanto à marca, pois ambas são experientes, isto é, sabem o que estão falando porque atingiram "a idade da razão".

Esse discurso de autoridade tem suas condições de êxito asseguradas, uma vez que se ancora em uma cena validada ${ }^{6}$ : a sabedoria dos mais velhos, os conselhos da vovó (como vovó dizia...) etc. Observe ainda que o "velho sábio" é em sua maioria referente ao homem idoso. A empresa então subverte essa lógica ao trazer uma senhora como fonte de sabedoria. Neste ponto, outros discursos são acionados. Sabe-se, por exemplo, que é o sexo feminino que mais sofre com a cobrança por um corpo escultural na praia; aquelas que não possuem tal corpo muitas vezes se sentem "intimidadas". Por meio dessa voz que convida mulheres a se divertir na praia independentemente da idade ou das formas corporais, podemos depreender um enunciador feminino libertário, isto é, que prioriza o bem-estar da mulher ao não se submeter aos padrões de beleza impostos.

Contudo, é em "Redondo é sair do seu passado" que esse novo posicionamento se legitima. Em 8 de março de 2017, Dia Internacional das Mulheres, a cervejaria da Ambev lança

\footnotetext{
${ }^{6}$ Recorremos a um conceito proposto por Maingueneau (2013, p. 102), que define cenas validadas como aquelas “[...] já instaladas na memória discursiva coletiva, seja a título de modelos que se rejeitam ou de modelos que se valorizam", isto é, cenas estereotipadas tanto positiva quanto negativamente, que estão "[...] disponíveis para reinvestimentos em outros textos". O idoso como fonte de sabedoria acumulada ao longo dos anos de vida é um estereótipo, haja vista os monges, anciões, curandeiros, gurus, velhos sábios etc., cujo arquétipo se encontra na psicanálise, na literatura e nas artes em geral, nos textos religiosos, filosóficos etc.
} 
"Reposter Skol". Nessa campanha, que tem o seu processo de criação e execução registrado em vídeo $^{7}$, a empresa convida oito ilustradoras a fim de recriar cartazes antigos da marca "sob um novo olhar", isto é, pela perspectiva feminina. Na descrição do filme, lê-se:

Precisamos falar sobre o passado.

Já faz alguns anos que a Skol não representa as mulheres de forma objetificada em seus pôsters, anúncios e comerciais. Mesmo assim, volta e meia essas imagens reaparecem nas redes sociais como se fossem atuais. Olhamos para o passado para reforçar que, seja num pôster de bar, num comercial de TV ou num post de internet, a única lente que importa é a do respeito. Hoje e sempre. Para isso, convidamos oito ilustradoras e artistas plásticas para recriarem alguns pôsters antigos de Skol sob um novo olhar: atual, poderoso, libertador. Reposter Skol. Redondo é sair do seu passado. (grifo nosso)

Se, por um lado, os antigos pôsteres incomodavam por retratar a mulher "objetificada" ou como serviçal do homem, por outro, incomodavam igualmente pela falta de diversidade, uma vez que se privilegiava somente um tipo de beleza. O projeto Reposter Skol conta com 14 pôsteres recriados com base em dois eixos: diversidade/inclusão e empoderamento feminino. Assim, tomamos para análise dois pôsteres em que essa proposta fica evidente (Figuras 3 e 4 ).

Antes, porém, de passarmos para os cartazes, são necessários alguns apontamentos. Nesta nova fase, como se verá, a empresa de fato busca outras perspectivas. Mas é interessante notar aquilo que a marca disponibiliza para se recriar e o que não vem à tona, ou seja, o que é dito e o que é silenciado. O projeto Reposter traz somente os pôsteres mais "amenos" do passado da marca. Por essa razão, buscamos para análise uma peça (Figura 1) que tenha reverberado e suscitado discussões. Feita essa ressalva, passemos para a Figura 3.

\footnotetext{
${ }^{7}$ Disponível em: https://www.youtube.com/watch?v=g 8fnMtbdso\&feature=youtu.be. Acesso em: 23 dez. 2018.
} 


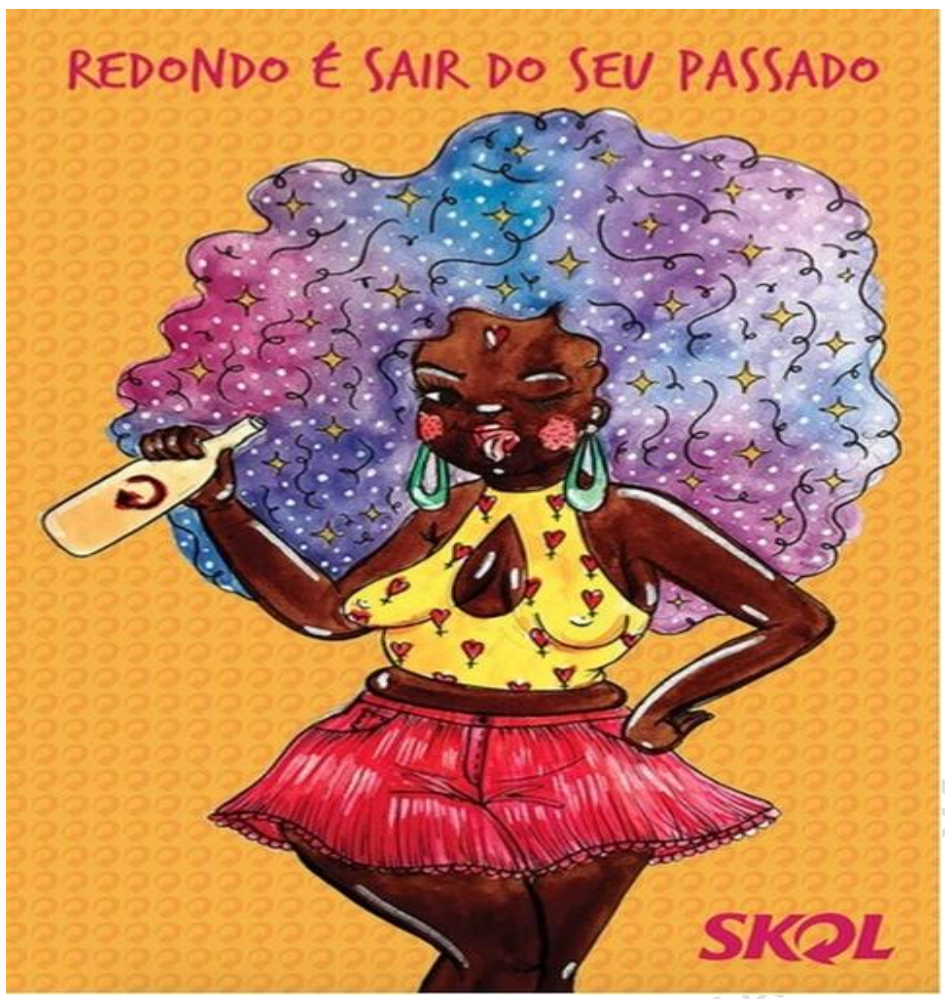

Figura 3.

Disponível em: www.skol.com.br/reposter. Acesso em: 9 mar. 2017.

Nesse cartaz, em primeiro plano, retrata-se uma jovem negra cujas medidas estão fora do padrão top model. Na parte superior da figura, encontra-se o slogan da campanha: "Redondo é sair do seu passado". Na parte inferior, à direita, está o logotipo da Skol. A jovem, cujo cabelo volumoso e psicodélico remete ao empoderamento da comunidade negra (Black Power), está vestida com saia rodada e mini blusa; na mão direita segura uma garrafa de cerveja.

Essa retratação não apenas inclui outras formas de beleza no anúncio, como também rompe com um padrão moral de comportamento na publicidade de cervejarias, segundo o qual a mulher é quem serve o homem de modo sensual, e não quem desfruta da bebida. Ademais, a feição da garota demonstra que ela está bem consigo mesma, ou seja, retratou-se um momento de autoaceitação e orgulho de si: libertador.

O slogan "Redondo é sair do seu passado" joga com a polissemia, pois refere-se simultaneamente

- à autodesconstrução, isto é, refletir sobre verdades de ontem e hoje;

- ao slogan "Redondo é sair do seu quadrado" (Figura 2), no quesito formal e semântico, visto que "quadrado", como abordamos anteriormente, é sinônimo popular de antiquado, ultrapassado, ou seja, de coisa relativa ao passado;

- ao passado sexista do qual a empresa tenta se descolar. 
Dessa maneira, funciona como um marco da mudança de posicionamento e ainda interpela o coenunciador, dado o seu caráter sentencioso, ou seja, ele exprime um imperativo moral, até revolucionário, o que não passa ao largo do mundo ético que se oferece.

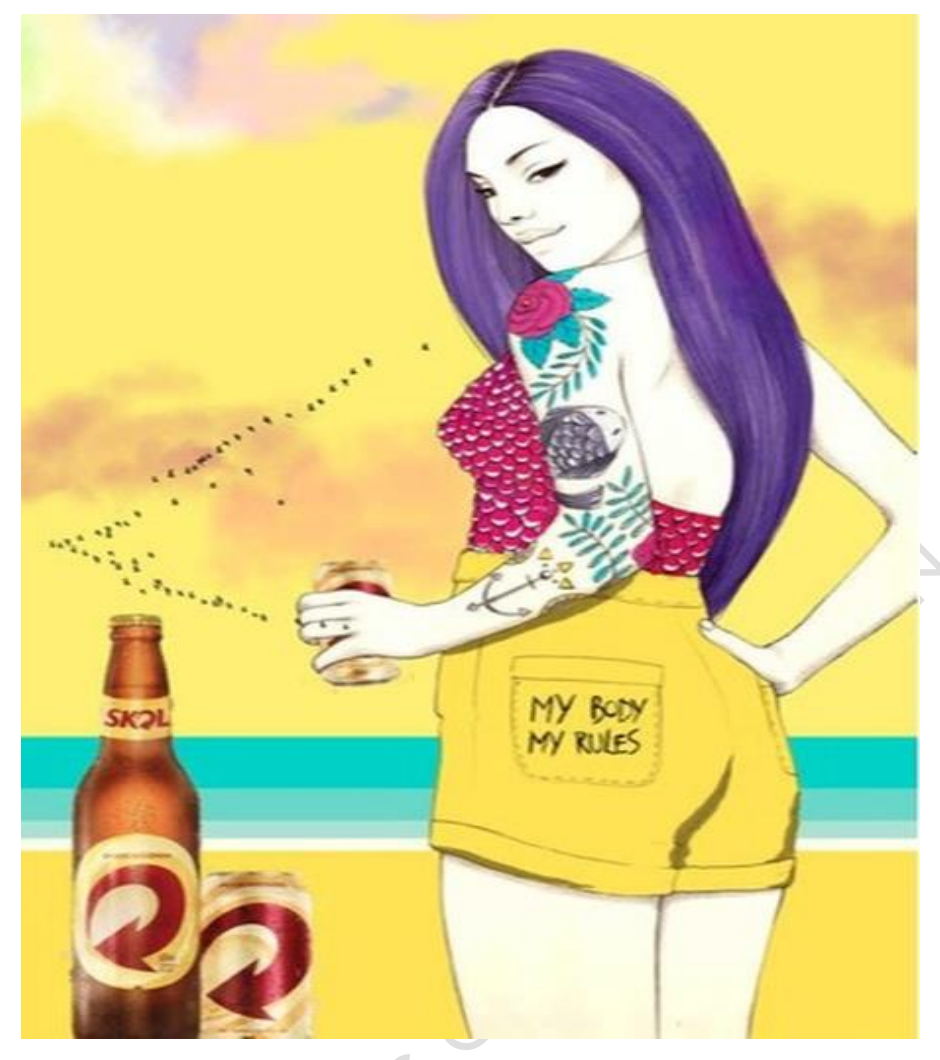

Figura 4.

Disponível em: www.skol.com.br/reposter. Acesso em: 9 mar. 2017.

A Figura 4 apresenta, em primeiro plano, em pé na praia, uma jovem caucasiana de cabelo comprido e pintado de roxo. Em seu braço esquerdo, destacam-se algumas tatuagens. Na mão esquerda, ela tem uma latinha de cerveja. Em seu short, pode-se ler o slogan feminista "My body My rules" (Meu corpo Minhas regras) ${ }^{8}$.

O cartaz rompe com o tradicional pelo simples fato de estampar um slogan feminista que denuncia o domínio masculino sobre o corpo feminino. É preciso observar também que esse pôster foi composto a partir de outro, um em que a modelo está na mesma posição, mas só de biquíni, ângulo propício para que partes do seu corpo fiquem salientes aos olhos do observador. Tal qual a Figura 3, esta põe a mulher não numa condição objetificada ou de serviçal, mas de alguém que curte a própria companhia ao apreciar uma cerveja na praia.

\footnotetext{
${ }^{8}$ Trata-se do título de uma animação britânica (Daniel Greaves e Ruth Beni, 2015) que denuncia a prática de mutilação genital de meninas em tenra idade. O slogan disseminou-se mundo afora em oposição ao controle e à legislação sobre o corpo feminino por parte do homem. O mote ganhou destaque no Brasil em decorrência das discussões travadas sobre a legalização do aborto na Argentina em meados de 2018.
} 
A partir da Figura 1 na relação com as demais, notamos uma subversão do gênero publicidade de cervejarias. Embora se trate da mesma empresa, são enunciadores distintos. E isso nos dá algumas pistas para discutir conceitos caros à noção de ethos discursivo. A primeira é compreender que, nos cartazes ora analisados, o ethos discursivo foi retificado, isto é, o ethos prévio bastante disseminado da empresa foi infirmado, e não atenuado. Caso não levassem o logotipo da marca, poder-se-ia dizer facilmente que se trata de outra empresa. De fato, transformou-se no seu oposto: Machista (2006) - Feminista (2016/2017); objetificação da mulher (2006) - empoderamento feminino/autonomia da mulher (2016/2017) etc.

Os traços finos e delicados, mas ao mesmo tempo firmes, juntamente com as cores vivas e floridas das Figuras 3 e 4 propiciam um tom feminino, de vivacidade, sem apelar para a sensualidade vulgar. Ademais, deve-se destacar a opção pela garota-propaganda não ser uma celebridade, mas mulheres “comuns", evidenciando que o ethos projetado está em sintonia com a conjuntura ideológica visada e, por isso, é imediatamente reconhecido/incorporado pela leitora. Em outras palavras, manteve-se uma coerência discursiva no ethos mostrado.

A inclusão de outras formas de beleza, tal qual a retratação da mulher como quem desfruta do produto anunciado, faz com que o fiador desse discurso emerja como feminista, mulher empoderada/autônoma. Desse modo, pessoas com esse perfil incorporam esse ethos, o qual lhes dá acesso ao mundo ético das mulheres empoderadas que trabalham, estudam, criam os filhos, autônomas quanto ao próprio corpo etc. e que bebem cerveja nos momentos de lazer e descontração. Dito de outra forma, trata-se de pessoas modernas, antenadas com os anseios sociais vigentes, sobretudo em relação à luta pela igualdade de gênero.

A empresa, por sua vez, projeta a imagem de si como moderna e revolucionária por romper com o passado; acolhedora por destacar públicos distintos na sua publicidade; e sobretudo feminista por empoderar as mulheres, veiculando a sua voz e os seus anseios diante da sociedade.

No 8 de março de 2018, a empresa tornou a levantar a bandeira feminista ao produzir um curta-metragem, Pra que escutar as minas?", no qual discute a "falta de voz" das mulheres em situações cotidianas. Foram convidadas mulheres de perfis diversificados para relatar os momentos em que não foram ouvidas pelo fato de ser mulher. O curta traz ainda depoimentos sobre a vida e carreira das participantes.

\section{Considerações finais}

\footnotetext{
${ }^{9}$ Disponível em: https://www.youtube.com/watch?v=GlkBwPksy5g. Acesso em: 26 dez. 2018.
} 
Neste texto, buscamos refletir sobre o processo de mudança de posicionamento da cervejaria Skol em relação à retratação do feminino em sua publicidade. Para tanto observamos, no material publicitário produzido entre 2016 e 2018, como as suas práticas discursivas tomaram um novo direcionamento e, deste modo, como se projetou uma nova imagem de si.

Ao refletirmos sobre esse processo de mudança, podemos pensar que essa formação discursiva visa a fazer o seu passado sexista recuar para a periferia, encontrando-se assim em uma fase de (re)constituição de identidade, uma vez que os suportes do discurso machista não se dissiparam. À medida que se expande a área semântica recoberta pelo discurso feminista, é comum que enunciados relacionados ao discurso machista sejam denegados ou mesmo atenuados. Mas, numa postura pouco ortodoxa no mundo da publicidade, a Skol não esconde o seu passado; pelo contrário, traz para o presente a fim de marcar o que, quando, como e porque mudou, ou seja, explora-o ao máximo a seu favor.

Por tratar-se de uma mudança abrupta, dada em um período relativamente curto, essa transmutação ou virada ética poderia se perder facilmente, tendo em vista a "descaracterização" da marca. Deste modo, justifica-se esse engendro enunciativo de abordar passado, presente e visão prospectiva no mesmo material para que a marca não se perca durante o processo, isto é, para que os consumidores saibam que ainda se trata da "mesma" marca de cerveja.

No interior de uma dada comunidade discursiva, busca-se gerenciar a forma de agir dos membros (práticas) e seu modo de enunciação (ethos). Contudo, é fato que a comunidade também sofre coerções externas, com as quais tem de lidar visando à sua manutenção. Logo, igualdade de gênero, autonomia feminina e inclusão da comunidade LGBTQI, por exemplo, são temas impostos a qualquer formação discursiva na atual conjuntura. Dessa forma, caso a Skol insistisse em suas práticas de outrora, poderia contabilizar prejuízos financeiros consideráveis em decorrência dos boicotes anunciados pelas consumidoras.

Como se sabe, a publicidade não se restringe a propagar informações sobre o produto oferecido; é também o meio pelo qual se veiculam ideologias, perspectivas sobre determinado tema/objeto, ou seja, um mundo ético no qual determinado produto faz todo sentido. Se, outrora, as empresas podiam permanecer neutras ou alheias a respeito de um movimento social, essa neutralidade aparente não é bem vista pelos consumidores atualmente, sobretudo em tempos de redes sociais, as quais possibilitam o contato direto entre consumidor e empresa.

Assim, a cobrança por uma postura coerente com o mundo ético posto a circular no material promocional é cada vez mais comum por parte dos consumidores. Em outras palavras, 
essa cobrança tornou-se uma prática discursiva: a empresa precisa agir segundo determinados parâmetros para se legitimar entre os clientes, formando com estes uma comunidade discursiva.

Tendo essas questões em mente, reproduzimos um trecho da entrevista promocional dada pela diretora de marketing da cervejaria aos grandes veículos de comunicação, na qual ela comenta o projeto Reposter Skol e a mudança de posicionamento da empresa. Após explicar o conceito do projeto e os seus objetivos, a diretora afirma: “[...] Não é uma forma de pedir desculpas, é uma forma de evoluir [ênfase acrescida] junto com o mundo, sem negar o que aconteceu de fato" ${ }^{10}$. Ou seja, esse passado já faz parte da memória dessa formação discursiva e com ele as novas gerações têm de lidar, mesmo que os novos projetos não o contemplem.

Mas é preciso explorar essa fala ainda mais de perto. Para isso, recorremos novamente a Maingueneau (2008a), que propõe que se tome o texto na articulação de um funcionamento discursivo e sua inscrição histórica, procurando pensar as condições de uma "enunciabilidade" passível de ser historicamente circunscrita. Devemos, então, partir de uma premissa básica: a Skol é uma corporação e, enquanto tal, sua finalidade é o lucro, o seu meio de sobrevivência.

No atual estágio do neoliberalismo, em que as empresas se digladiam por uma fatia maior no mercado, o emprego do item lexical "evoluir", destacado, é bastante significativo. Além de sua acepção atual (evoluir = melhorar, aperfeiçoar-se, acompanhar sincronicamente etc.), não podemos negligenciar aquela relacionada à Teoria da Evolução (seleção natural) preconizada por Charles Darwin, segundo a qual os organismos mais bem adaptados ao ambiente têm maiores chances de sobrevivência.

À medida que o discurso sexista sofre abalos pelas razões postas anteriormente, o organismo Skol precisa "evoluir junto com o mundo", isto é, adaptar-se ao meio para sobreviver. Por ser líder em seu segmento empresarial, a companhia precisa expandir seus horizontes e conquistar novos mercados. Daí a oportunidade de evoluir para outros nichos/ segmentos, como os que têm sido contemplados no pós-carnaval 2015.

Logo, somos levados a problematizar esse novo posicionamento e, por conseguinte, o ethos discursivo. Assumir o passado e prometer melhorias provoca uma mudança de atitude e, simultaneamente, imprime um certo tom de nobreza à marca. Contudo, pode-se pensar também que "Redondo é sair do seu passado [quadrado]" é um convite ao potencial consumidor que está em consonância com o ethos proposto. Enfim, trata-se de apontar para grupos minoritários,

10 Disponível em: https:/g1.globo.com/economia/midia-e-marketing/noticia/skol-lanca-acao-para-trocarcartazes-machistas-de-bares.ghtml. Acesso em: 26 dez. 2018. 
até então excluídos do discurso publicitário, que existe uma marca de cerveja que os entende, que os representa e que os acolhe, com os quais é possível formar uma comunidade.

Sublinhe-se que essa mudança de paradigma comercial agradou ao público, um fato que pode ser atestado nas milhões de visualizações de seus vídeos no canal da marca no Youtube e nos comentários em suas páginas nas redes sociais.

Se essa mudança corresponde ao cotidiano da empresa ou não (igualdade salarial, de gênero, dentre outros), não podemos precisar. O que fica para nós é como a mudança de suas práticas e consequentemente do ethos - construído no e pelo discurso - é engendrado e posto a circular no material publicitário da Skol, a fim de persuadir um público que pode ignorá-lo ou rejeitá-lo a qualquer momento.

Resta-nos, portanto, apenas um fato: no atual contexto sócio-histórico, negligenciar a comunidade LGBTQI e o público feminino definitivamente não é um bom negócio.

\section{REFERÊNCIAS}

AMOSSY, R (org.). Imagens de si no discurso: a construção do ethos. 2. ed. São Paulo: Contexto, 2014.

Charaudeau, P.; MAIngueneaU, D. Dicionário de Análise do Discurso. 3. ed. São Paulo: Contexto, 2012.

GABRIEL, E. G. Frases sem texto na publicidade: discursos em torno de um Brasil bilíngue. 2018. 132f. Dissertação (Mestrado em Linguística Aplicada e Estudos da Linguagem)

- Programa de Estudos Pós-Graduados em Linguística Aplicada e Estudos da Linguagem, Pontifícia Universidade Católica de São Paulo, São Paulo, 2018.

MAINGUENEAU, D. Gênese dos Discursos. São Paulo: Parábola Editorial, 2008a.

MAINGUENEAU, D. Problemas de ethos. In: MAINGUENEAU, D. Cenas da enunciação. POSSENTI, S.; SOUZA-E-SILVA, M. C. P. (orgs.) 2. ed. São Paulo: Parábola Editorial, 2008 b. p. $55-73$.

MAINGUENEAU, D. A propósito do ethos. In: MOTTA, A. R.; SALGADO, L. S. (orgs.). Ethos discursivo. São Paulo: Contexto, 2008c. p. 11-29.

MAINGUENEAU, D. Análise de textos de comunicação. 6. ed. ampliada. São Paulo: Cortez, 2013.

MAINGUENAU, D. Ethos, cenografia e incorporação. In: AMOSSY, R (org.). Imagens de si no discurso: a construção do ethos. 2. ed. São Paulo: Contexto, 2014. p. 69-92. 
MAINGUENEAU, D. Retorno crítico sobre o ethos. In: BARONAS, R. L; MESTI, P. C.; CARREON, R. de O. (orgs.). Análise do Discurso: entorno da problemática do ethos, do político e de discursos constituintes. Campinas: Pontes Editores, 2016. p. 13-34.

MENDES, S. R. C.; GABRIEL, E. G. Ethos discursivo na publicidade: uma imagem, uma polêmica. In: Letras de Hoje. v. 53, n. 3, p. 440-448, jul.-set. 2018. Disponível em: http://revistaseletronicas.pucrs.br/ojs/index.php/fale/article/view/30926/17637. Acesso em: 25 jan. 2019.

\title{
FEMININE IN BEER ADVERTISING: IN SEARCH OF LOST ETHOS
}

\begin{abstract}
Feminist struggle for gender equality has changed the manner that beer companies show women in their advertisings in the early $21^{\text {st }}$ Century. This paper has two goals: To analyse the enunciative strategies that support Skol's position change in relation to the feminine retraction in its advertisings and to reflect critically on the possibility of such change considering the current sociohistorical context. It is based on French Discourse Analysis in its enunciative-discursive aspect, as it is proposed by Dominique Maingueneau, from whom I trigger the notion of Discursive Ethos. Corpus is collected digitally and consists of Skol's posters that circulated at different times. Results show that, in addition to ethical and moral reasons in line with the present times, the change from a more sexist position to a feminist one may have been caused mainly by economic issues.

Keywords: French Discourse Analysis. Discursive Ethos. Sexism and objectification of women's body in beer advertisings.
\end{abstract}

